\title{
Social Comparison Orientation in Monozygotic and Dizygotic Twins
}

\author{
Pascal Huguet, ${ }^{1, *}$ Michèle Carlier, ${ }^{2, *}$ Conor V. Dolan, ${ }^{3}$ Eco J. de Geus, ${ }^{3}$ and Dorret I. Boomsma ${ }^{3}$ \\ ${ }^{1}$ University Clermont Auvergne and CNRS, LAPSCO, Clermont-Ferrand, France \\ ${ }^{2}$ Aix Marseille University, CNRS, LPC, Cognitive Psychology, Marseille, France \\ ${ }^{3}$ Vrije Universiteit, Netherlands Twin Register \& Department of Biological Psychology, Amsterdam, the Netherlands
}

\begin{abstract}
Twin research has offered evidence that monozygotic (MZ) twins are more socially close than dizygotic (DZ) twins, but has not paid much attention to the way twins compare themselves with their co-twin. The few studies in this area suggest that 'horizontal comparisons' (social comparison motivated by solidarity or communion with others) matter more for MZ twins than for DZ twins, at least when the co-twin is the social comparison standard. Consistent with this view, we predicted higher interest in MZ twins relative to DZ twins to select their co-twin rather than other people in general as the social comparison standard. The Social Comparison Orientation (SCO) scale, which measures the inclination to compare with others in a horizontal rather than vertical mode (comparing either upward or downward), was administered in $90 \mathrm{MZ}$ pairs and 57 same-sex DZ pairs (63\% female; average age 18.06 years) from the Netherlands Twin Register. MZ twin pairs showed significantly higher SCO scores than DZ twin pairs (with a large effect size) on the co-twin SCO, whereas the two groups did not differ from each other on the general SCO excluding the co-twin as social comparison standard. In MZ twin pairs, anxiety was associated with social comparison with others in general, not with their co-twin. For both scales, twin resemblance was explained by additive genetic variance. The present findings provide direct evidence that horizontal comparisons with the co-twin are of particular importance for MZ twins.
\end{abstract}

Keywords: social relationships, social comparison, SCO scale

It has long been known that twins may share a special kind of social relationship compared to non-twin siblings. Monozygotic (MZ) twins have on average closer relationships than dizygotic (DZ) twins, who themselves have closer relationships than non-twin siblings (Fortuna et al., 2010; Fraley \& Tancredy, 2012; Loehlin \& Nichols, 1976; Mowrer, 1954; Neyer, 2002; Penninkilampi-Kerola, 2005; Segal, 1984; Segal et al., 2013; Tancredy \& Fraley, 2006; Thorpe, 2003; Zazzo, 1960, 1976). Compared with DZ twins and non-twins, MZ twins also show greater cooperation (Segal, 1984) and more tacit coordination with their co-twin during childhood, adolescence, and in older age (McGuire \& Segal, 2013; Segal et al., 2008, 2013, 2014). This higher interdependency between $\mathrm{MZ}$ twins relative to $\mathrm{DZ}$ twins can also be found in pairs separated in infancy and reunited later (Segal et al., 2003).

Because MZ twins share nearly all their genes while DZ twins share on average $50 \%$ of their segregating genes, people expect MZ twins to be more similar than $\mathrm{DZ}$ twins for any trait that is influenced by genes. The label 'identical' when talking about $\mathrm{MZ}$ is a good illustration of this expectation that leads parents, other family members, teach- ers, and friends to compare the twins on various characteristics, such as height, weight, skills and abilities, and social behavior (Ebeling et al., 2003; Stewart, 2000). Although these pressures towards uniformity may encourage and even force the twins to compare with their co-twin, this comparison did not receive much attention in twin research. This is relatively surprising as the non-volitional nature of 'twinship' also means that this comparison is often unavoidable (Noller et al., 2008).

\section{Social Comparison among Twins}

Noller and colleagues (Noller, 2005; Noller \& BlakelySmith, 2007; Noller et al., 2008) collected retrospective self-reports of situations of asymmetrical (upward or

RECEIVED 21 September 2017; ACCEPTED 10 October 2017. First published online 10 November 2017.

ADDRESS FOR CORRESPONDENCE: Pascal Huguet, University Clermont Auvergne and CNRS, LAPSCO, F-63000 ClermontFerrand, France. E-mail: pascal.huguet@uca.fr.

${ }^{*}$ These authors contributed equally. 
downward) social comparisons and competition with their emotional component among same-sex sibling pairs (twins, adolescent and young adult siblings), which also allowed these authors to test Tesser's Self-Evaluation Maintenance (S-EM) model (Tesser, 1988; Tesser \& Schartz, 2001). According to this model, when one is outperformed by a close other on a task high in relevance to the self, a potentially self-threatening social comparison is created. When another outperforms on a task low in relevance to the self, the closer the other the greater the 'self-reflected glory', a reflection (rather than comparison) process where individuals benefit from their close others' successful performance. As reported by Noller and colleagues (Noller, 2005; Noller et al., 2008), DZ twins and non-twins' reports were generally consistent with the S-EM model whereas MZ twins' reports were not. MZ twins tended on average to react positively to upward comparisons with their co-twin on selfrelevant dimensions, suggesting that the very close relationship with their co-twin 'buffered them against any problems related to competition and comparison' (Noller et al., 2008, p. 249; see also Veldkamp et al., 2017).

Complementary with Noller and colleagues' approach, Watzlawik (2009) examined what adolescent siblings actually perceive when they compare themselves with their counterparts, and found that MZ co-twins perceived fewer differences between them than did DZ co-twins and nontwin siblings. Although MZ twins did not perceive more similarities, they were the only group where the selfreported similarities outweighed the differences. As noted by Watzlawik (2009), MZ twins may 'have more difficulties in finding their individual niches - which does not necessarily have to be a disadvantage since the twin relationship offers a special support as well' (p. 574).

\section{The Present Research}

Although the tendency to engage in social comparison is thought to be a universal human characteristic (Gilbert et al., 1995) - a 'phylogenetically very old' and 'biologically very powerful' tendency (to take Gilbert et al.'s own words) - there is evidence that the strength of this tendency varies between individuals (Gibbons \& Buunk, 1999). In line with this idea, Gibbons and Buunk (1999) developed the IowaNetherlands Comparison Orientation scale (hereafter referred to as SCO scale), measuring the inclination or willingness to compare one's accomplishment, situations, or experiences with those of others. The social comparison orientation (SCO) scale includes 11 items, such as 'I always like to know what others in a similar situation would do', and 'I often compare myself with others with respect to what I have accomplished in life. Based on a representative sample of Dutch citizens in all age groups, it revealed that there are as many high comparers as there are low comparers. Inter-items reliability (Cronbach's alpha) was very consistent across a variety of samples, ranging from $0.78-0.85$ in the United States and the Netherlands. Likewise, test- retest correlations ranged from 0.71 for 3-4 weeks to 0.60 for a year in the United States (and Spain) and to 0.72 for 7.5 months in the Netherlands. The SCO scale was then adapted and successfully used in many countries; for example, Hungary, Poland, Turkey (Luszczynska et al., 2004), Spain (Buunk et al., 2005), and France (Jonas \& Huguet, 2008), to name but a few.

Of particular interest here, Buunk and Gibbons (2006) found that the SCO scale is associated with an interpersonal orientation, a construct that includes a strong empathy for others, a general sensitivity to the needs, moods, and criticisms of others, and an interest to mutual self-disclosure all aspects that are typical of individuals with a high interdependent self (Markus \& Kitayama, 1991; Swap \& Rubin, 1983). As would be expected from the individuals with an interdependent self, Buunk and Gibbons (2006) also found that the SCO scale correlates positively with the communal orientation scale (Clark et al., 1987) measuring the inclination to care and help others. This pattern of correlations (the higher SCO scores, the higher interdependence, and communal values) may seem counter-intuitive, as also pointed out by Buunk and Gibbons (2006), since social comparison has traditionally been associated with a motivation toward differentiating oneself in a competitive way from others.

However, there is today ample evidence that two broad, independent dimensions underlie social comparison processes: a 'vertical' (better/worse than others) dimension of status, dominance, or agency (see Buunk et al., 1990; Mussweiler, 2003; Suls et al., 2002; Wills, 1981; Wood, 1989), and a 'horizontal' dimension of solidarity, friendliness, or communion (for a review, see Locke, 2014). In light of this useful distinction, it can reasonably be assumed that the SCO scale reflects the horizontal (more than vertical) dimension of social comparison. If $\mathrm{MZ}$ twins are more interdependent with their co-twin than are DZ twins, we reasoned, $\mathrm{MZ}$ twins should then score higher than $\mathrm{DZ}$ twins on a version of the SCO scale focusing specifically on the co-twin as social comparison standard. Likewise, MZ twins (but not necessarily DZ twins) should be higher on this co-twin version of the SCO scale than on its classic (general) version measuring the willingness to compare with people 'in general'. Higher level of SCO towards the co-twin among MZ twins relative to DZ twins would clarify the meaning of social comparison among twins, and show its dependency on zygosity.

\section{Materials and Methods}

\section{Participants}

Participants were 147 young adult same-sex twin pairs (14.87-22.68 years of age, $M=18.06, S D=1.53)$ recruited from the Netherlands Twin Registry (Boomsma et al., 2006) as part of a larger study on the development of attention and cognition. The sample included $90 \mathrm{MZ}$ pairs (30 MZ male pairs [MZ-M], $60 \mathrm{MZ}$ female pairs [MZ-F]) 
and 57 same-sex dizygotic (SSDZ) twin pairs (23 SSDZ male pairs [SSDZ-M] and 34 SSDZ female pairs [SSDZF]). The four groups did not differ on age or non-verbal intelligence evaluated in a computerized form of the Raven advanced progressive matrices (Bartels et al., 2012). None of the participants suffered from severe physical or mental handicaps. Prior to the study, participants and their parents (for participants under 18 years) signed an informed consent form. Zygosity was determined on the basis of DNA polymorphisms.

\section{Measures}

All data were collected at the Vrije Universiteit, Amsterdam. Participants from each pair were tested at the same time, independently in separate rooms. They performed a reasoning test (advanced Raven matrices) and then answered a short questionnaire including a measure of test-related anxiety (Spielberger et al., 1970; see appendix A) and the two versions of the SCO scale: the standard version assessing individual differences in SCO with others in general (thus excluding the co-twin), and a modified version where the words 'others' (or equivalent terms) were replaced by 'my co-twin' (hereafter referred to as general SCO and co-twin SCO, respectively, see appendix B). For both versions (11 items in each version), each participant indicated to what extent he/she agreed or disagreed with each item. Gibbons and Buunk (1999) used a 5-point scale for the general SCO that ranged from 1 (strongly disagree) to 5 (strongly agree). In the present study, we used a 6-point scale $(1=$ strongly agree, $2=$ agree, $3=$ mostly agree, $4=$ mostly disagree, $5=$ disagree, and $6=$ strongly disagree) to increase the discriminative power of the two versions of the SCO scale and avoid the use of a midpoint score (neither agree or disagree). The SCO scores therefore indicated higher SCO either with the co-twin (co-twin SCO) or with others in general excluding the co-twin (general SCO). Cronbach's alphas (taking the twin pair as unit of analysis) were high for the two versions of the SCO scale $(\alpha \mathrm{MZ}=0.88$ and $\alpha \mathrm{DZ}=0.78$ for the general SCO; 0.91 and 0.90, respectively, for the co-twin SCO). The two versions of the SCO scale were administered after the reasoning test for all participants so as not to explicitly prime social comparison-related cognitions during test performance.

\section{Statistical Analysis}

We carried out two analyses of variance (ANOVAs) with the mean of the twin pair as the unit of analysis. The first ANOVA was a $2 \times 2$ mixed design using zygosity (MZ vs. $\mathrm{DZ}$ ) as an independent variable and type of SCO scale (Cotwin vs. General) as repeated measures. We performed a second mixed design ANOVA while adding twin pairs' sex as independent variable. We note that the variance of the twin means is expected to vary as a function of zygosity, with the $M Z$ variance being greater than the $D Z$ variance. This implies a possible violation of homogeneity of error

\begin{tabular}{|c|c|c|c|c|c|}
\hline \multicolumn{6}{|c|}{$\begin{array}{l}\text { Means and Standard Deviations for the } \\
\text { Versions of the SCO Scale by Zygosity }\end{array}$} \\
\hline \multirow[b]{2}{*}{ Zygosity } & \multirow{2}{*}{$\begin{array}{l}\text { Number } \\
\text { of pairs }\end{array}$} & \multicolumn{2}{|c|}{ General SCO } & \multicolumn{2}{|c|}{ Co-twin SCOpt } \\
\hline & & Mean & $S D$ & Mean & $S D$ \\
\hline $\mathrm{MZ}$ & 90 & 44.07 & 6.50 & 45.71 & 8.21 \\
\hline $\mathrm{DZ}$ & 57 & 43.82 & 4.39 & 39.32 & 7.61 \\
\hline
\end{tabular}

variances. To determine whether the results of the ANOVAs were affected by this violation, we repeated the analyses using the sandwich correction implemented in the SPSS generalized estimating equations (GEE) procedure (e.g., Dobson \& Barnett, 2008). Relations between SCO and anxiety were described with Person correlations. Twin correlations were calculated for $\mathrm{MZ}$ and $\mathrm{DZ}$ pairs, and genetic analyses were carried out in $\mathrm{Mx}$ (Neale et al., 2006) for both versions of SCO to estimate the contribution of genetic and environmental factors to population variance in these scores.

\section{Results}

\section{Social Comparison Orientation (SCO Scales)}

In the first mixed design ANOVA all effects were significant: zygosity, $F(1,145)=10.52, p=.0014$, partial $\eta^{2}=0.07$, SCO scale, $F(1,145)=6.06, p=.015$, partial $\eta^{2}=0.04$, and zygosity by SCO scale interaction, $F(1,145)=28.06$, $p<.0001$, and partial $\eta^{2}=0.16$. Using GEE we obtained the following test statistics: zygosity, $\chi^{2}(1)=12.09, p<$ .001 ; SCO scale, $\chi^{2}(1)=6.06, p=.015$, and the interaction: $\chi^{2}(1)=27.28, p<.0001$. The conclusions based on the ANOVA are therefore the same as those based on GEE.

Table 1 shows the four means and standard deviations. Consistent with our expectations, on the co-twin SCO scale, MZ twins showed higher scores than DZ twins, $t(145)=$ $4.73, p<.0001$, Cohen's $d=0.73$, whereas both groups $\mathrm{did}$ not differ on the general SCO scale, $t(145)=0.26, p=.80$, $d=0.05$. Likewise, $\mathrm{MZ}$ twins showed higher scores on the co-twin SCO scale than on the general SCO scale, paired $-t(89)=2.37, p=.02, d=0.35$, whereas actually the reverse effect occurred in DZ twins, paired $-t(56)=-4.68$, $p<.0001, d=0.88$.

The statistical analysis, which included twin pairs' sex, revealed that female pairs scored higher than male pairs whatever the version of the SCO scale, $F(1,143)=14.35$, $p<.0001$, and $\eta_{p}{ }^{2}=0.09$ (on average on both scales, $M=$ 44.6, $\mathrm{SEM}=0.62$ for females, and $M=40.78, \mathrm{SEM}=0.80$, for males), with no significant zygosity $\times \mathrm{SCO} \times$ sex interaction, $F(1,143)=1.48, p=.23$, and $\left.\eta_{p}{ }^{2}=0.01\right)$. Using GEE we obtained the following test statistics: main sex effect: $\chi^{2}(1)=15.74, p<.001$; the 3 -way interaction: $\chi^{2}(1)$ $=1.57, p=.21$. Once more, the ANOVA results and GEE results give rise to the same conclusions.

Although the first-born and the second-born co-twins have essentially the same age, they may define themselves as the younger or the elder (Noller et al., 2008; Stewart, 
2000; Yoon \& Hur, 2006). We thus conducted a $2 \times 2$ mixed ANOVA design using zygosity (MZ vs. DZ) as an independent variable and type of SCO scale (Co-twin vs. General) as repeated measures separately for the younger twins and their elder counterparts. We found the same results as previously. In both age groups, MZ twins showed higher scores than DZ twins ( $p s \leq .001)$ on the co-twin SCO scale, whereas $\mathrm{MZ}$ and $\mathrm{DZ}$ twins did not differ on the general SCO scale ( $p$ s $\geq .27$ ). Likewise, in both age groups, MZ twins showed a higher score on the co-twin SCO scale than on the general SCO scale (especially the second-born; first-born, $p$ $=.10, d=0.24$; second-born, $p=.01, d=0.37$ ), whereas the reversed effect was found in the first- and second-born DZ twins ( $p s \leq .001, d=0.67$ and 0.78 , respectively).

\section{Self-Reports of Anxiety}

As noted by Buunk and Gibbons (2006), responses on the general SCO scale also correlate with anxiety and neuroticism, although these correlations are lower than those with interpersonal and communal orientations. In line with this, the MZ twin pairs' SCO scores correlated positively and significantly with their reports of anxiety for both versions of the scale, $r \mathrm{~s}(88)=0.39, p<.001$ and $0.30, p=.004$, for the general and co-twin versions of the SCO scale, respectively. However, the co-twin SCO-anxiety relationship was no longer significant, $r(87)=0.08, p=.45$, when controlling for the general SCO, whereas the general SCO-anxiety relationship remained significant, $r(87)=0.28, p=.009$, when controlling for the co-twin SCO. This indicates that MZ twins' anxiety was associated with social comparison with others in general, but not with their co-twin. The SCOanxiety relationships did not reach significance in DZ twins, $r s(55)=0.05$ and $0.16, p s^{\prime}>.24$, for the general and cotwin versions of the SCO, respectively.

\section{Twin Correlations (ICC) and Genetic Analyses}

$\mathrm{MZ}$ intraclass correlations were larger than DZ intraclass correlations for both scales. Co-twin version: 0.585 (95\% CI [0.43, 0.71]) versus 0.271 (95\% CI [0.013, 0.494]); general version: $0.616(95 \% \mathrm{CI}[0.469,0.729])$ versus 0.004 (95\% CI $[-0.255,0.262])$. For the co-twin version heritability was estimated at $59 \%$ and for the general version at $56 \%$, with the remaining variance explained by non-shared environment.

\section{Discussion}

Twin research offers evidence that MZ twins are more socially interdependent than DZ twins, but has not paid much attention to the way twins compare themselves with their co-twins. The few studies in this area indicated that MZ twins, but not DZ twins, can benefit from their co-twin's success even when it occurs in self-relevant comparison dimensions (Noller et al., 2008), suggesting that MZ twins' close relationship with their co-twin actually protects them against any problems related to interpersonal competition.
Consistent with decades of research on twins relationships, this finding and others (Watzlawik, 2009) seemed to indicate that MZ twins are more likely than DZ twins to experience social comparison with their co-twin in a horizontal mode motivated by solidarity or communion (see Locke, 2003,2014 ), as opposed to a vertical mode (comparing either upward or downward for a variety of reasons mostly related to status, dominance, or agency; see Buunk et al., 1990; Mussweiler \& Rüter, 2003; Suls et al., 2002; Wills, 1981; Wood, 1989, 1996). The present findings strengthen this view.

In the SCO scale measuring mainly empathy for others - a special sensitivity to the needs, moods, and criticisms of others - and interest in mutual self-disclosure, we reasoned that MZ twins should display higher SCO scores than DZ twins when focusing specifically on their co-twin as a social comparison standard. This is exactly what we found. MZ twin pairs showed significantly higher SCO scores than DZ twin pairs (with a large effect size) on the co-twin SCO, whereas the two groups did not differ from each other on the general SCO excluding the co-twin as social comparison standard. This dissociation rules out any characterization of MZ twins as simply more interested than DZ twins by horizontal comparisons with people in general. ${ }^{1}$ Consistent with this special interest of MZ twins in horizontal comparisons with their co-twin specifically, they also scored higher on the co-twin SCO relative to the general $\mathrm{SCO}$, whereas the reverse effect was found in DZ twins. Furthermore, whereas higher interest in horizontal comparisons with the co-twin was unrelated to $\mathrm{MZ}$ and $\mathrm{DZ}$ twins' self-reports of anxiety, this relationship proved significant and positive in $\mathrm{MZ}$ twins for comparisons excluding the cotwin (general SCO). Taken together, these findings can reasonably be taken as evidence that horizontal comparisons with the co-twin are of particular importance for MZ twins.

This conclusion does not mean that MZ twins never engage in vertical comparisons (upward or downward) with their co-twin (as also suggested by Watzlawik, 2009). The tendency to compare upward (i.e., with someone better off in a given domain), for example, is a powerful trend (Blanton et al., 1999; Festinger, 1954; Huguet et al., 2001; 2009), which occurs early in cognitive development (Dumas et al., 2005). As with many other individuals, MZ twins may deliberately engage in upward comparisons, at least with their co-twin, simply because these comparisons can reveal useful information about how to improve in such and such a domain (e.g., Buunk \& Ybema, 1997; Taylor \& Lobel, 1989; Wood, 1989). In non-twins or singletons, the reasons for choosing to compare upward and that might result in improved performance are numerous. As noted by Blanton et al. (1999), individuals may come to identify with successful targets (leading to imitation of the targets' actions; Bandura, 1986), and/or set higher personal standards for evaluating their own success, which can motivate efforts toward these more challenging goals (e.g., Dumas 
et al., 2005; Huguet et al., 1999, 2000; Seta, 1982). Observing others doing well can also endow individuals with a sense of their own potential (e.g., Buunk et al., 1990; Lockwood \& Kunda, 1997; Major et al., 1991), which may raise self-confidence and feelings of self-efficacy, with positive consequences on performance (see Multon et al., 1991; Schunk, 1989). All these effects are likely in MZ twins due to the very close relationship with their co-twin conceived as a social comparison standard. As also noted by Locke (2014), sharing a close relationship (Mussweiler \& Rüter, 2003; Pelham \& Wachsmuth, 1995), potentially sharing the same fate (Lockwood \& Kunda, 1997), sharing membership in a distinguishing and self-defining group (Brewer \& Weber, 1994; Mussweiler \& Bodenhausen, 2002), and sharing other rare or distinctive attributes (Brown et al., 1992) have all been shown to enhance assimilation, especially upward assimilation (increased self-evaluation and/or performance following upward comparison), as opposed to upward contrast (decreased self-evaluation and/or performance following upward comparison; see also Huguet et al., 2009; Mussweiler, 2003; Wheeler \& Suls, 2007). Although the present findings indicate that horizontal comparisons with their co-twin is of particular importance in MZ twins, there are therefore good reasons to believe that $\mathrm{MZ}$ twins may also engage in vertical comparisons with beneficial effects on cognition, motivation, and emotion.

As suggested by Noller et al.'s (2008) findings, upward assimilation also seems to occur in MZ twins (but not in DZ twins) even when upward comparisons with the co-twin are forced by the social environment, a condition typically associated in non-twins or singletons with upward contrast and so negative effects on self-evaluation and performance (see Huguet et al., 2009; Marsh \& Hau, 2003). Strongly motivated by horizontal comparisons emphasizing solidarity and communion with their co-twin, MZ twins, perhaps more than any other models of close relationships, are thus likely to benefit from upward comparisons with their co-twin even when these comparisons are forced rather than deliberate.

Future research, however, is needed to estimate the moderating role of horizontal comparisons operating within twin pairs on the influence of vertical comparisons, especially those arising under the pressure of the social environment. Likewise, future research might help specify the role - if any - of horizontal comparisons in phenomena, such as the tacit coordination that typically occur within twins pairs, or the self-confidence that twins may derive from their co-twin, to name but a few. For example, Locke (2005) showed in non-twins or singletons that perceiving similarities with a social comparison standard's desirable attributes, and dissimilarities with undesirable attributes, enhanced self-confidence. Ironically, assimilation being the default mindset within MZ twin pairs, MZ twins may perceive similarities with the co-twin's desirable as well as undesirable attributes, resulting in decreased self-confidence when the salience of undesirable attributes prevail for some reasons. Thus, although social comparison is a fundamental feature of social life in humans, perhaps especially in twins, much remains to be done to integrate it with our understanding of twins' relationships.

\section{Acknowledgments}

We warmly thank all twins who took part in the study and Tinca Polderman, Aafke van Santen, and Felice van Weegen for data collection. This work was supported by ANR grant Twins-2010 (P. H., M.C.), Aix Marseille University (P. H., M.C.), CNRS (P.H., M.C.), Vrije University, Netherlands Twin Register \& Department of Biological Psychology (C.D., E.G., D.B).

\section{Conflict of Interest}

None.

\section{Ethical Standards}

The authors assert that all procedures contributing to this work comply with the ethical standards of the relevant national and institutional committees on human experimentation and with the Helsinki Declaration of 1975, as revised in 2008. The study was approved by the Central Committee on Research Involving Human Subjects, and the institutional review board of the VU University Amsterdam.

\section{Endnote}

1 The fact that female pairs (both MZ and DZ) scored higher than male pairs whatever the version of the SCO scale (cotwin vs. general) strengthens the view that this scale measures an interpersonal orientation rather than competition. There is indeed ample evidence that male and female (culturally mandated) sense of self depends on separation and independence for men, and connection and interdependence for women (see Maccoby \& Jacklin, 1974; Markus \& Kitayama, 1991; Swap \& Rubin, 1983), with strong implications early in the course of cognitive development (e.g., Huguet \& Monteil, 1995).

\section{References}

Bandura, A. (1986). The explanatory and predictive scope of self-efficacy theory. Journal of Social and Clinical Psychology, 4, 359-373.

Bartels, M., van Weegen, F. I., van Beijsterveldt, C. E., Carlier, M., Polderman, T. J., Hoekstra, R. A., \& Boomsma, D. I. (2012). The five factor model of personality and intelligence: A twin study on the relationship between the two constructs. Personality and Individual Differences, 53, 368373.

Blanton, H., Buunk, B. P., Gibbons, F.X., \& Kuyper, H. (1999). When better-than-others compare upward: Choice of comparison and comparative evaluation as independent predictors of academic performance. Journal of Personality and Social Psychology, 76, 420-430. 
Boomsma, D., Geus, E., Vink, J., Stubbe, J., Distel, M., Hottenga, J., ... Willemsen, G. (2006). Netherlands twin register: From twins to twin families. Twin Research and Human Genetics, 9, 849-857.

Brewer, M. B., \& Weber, J. G. (1994). Self-evaluation effects of interpersonal versus intergroup comparison. Journal of Personality and Social Psychology, 66, 268-275.

Brown, J. D., Novick, N. J., Lord, K. A., \& Richards, J. M. (1992). When Gulliver travels: Social context, psychological closeness, and self-appraisals. Journal of Personality and Social Psychology, 62, 717-727.

Buunk, A. P., \& Gibbons, F. X. (2006). Social comparison orientation: A new perspective on those who do and those who don't compare with others. In S. Guimond (Ed.), Social comparison and social psychology: Understanding cognition, intergroup relations, and culture (pp. 15-32). New York, NY: Cambridge University Press.

Buunk, B. P., Collins, R. L., Taylor, S. E., Van Yperen, N. W., \& Dakof, G. A. (1990). The affective consequences of social comparison: Either direction has its ups and downs. Journal of Personality and Social Psychology, 59, 12381249.

Buunk, B. P., \& Ybema, J. F. (1997). Social comparison and occupational stress: The identification-contrast model. In B. P. Buunk \& F. X. Gibbons (Eds.), Health, coping, and wellbeing: Perspectives from social comparison theory (pp. 359388). Mahwah, NJ: Erlbaum.

Buunk, B. P., Zurriaga, R., Peíró, J. M., Nauta, A., \& Gosalvez, I. (2005). Social comparisons at work as related to a cooperative social climate and to individual differences in social comparison orientation. Applied Psychology, 54, 6180.

Clark, M. S., Ouellette, R., Powell, M. C., \& Milberg, S. (1987). Recipient's mood, relationship type, and helping. Journal of Personality \& Social Psychology, 53, 94-103.

Dobson, A. J., \& Barnett, A. (2008). An introduction to generalized linear models (3rd ed.) Boca Raton, FL: Chapman \& Hall/CRC Texts in Statistical Science.

Dumas, F., Huguet, P., Monteil, J. M., \& Ayme, E. (2005). Context effects in the Stroop task: Knowledge of one's relative standing makes a difference. Current Psychology Letters: Cognition, Brain, \& Behavior, 16, 1-12.

Dumas, F., Huguet, P., Monteil, J.-M., Rastoul, C., \& Nezlek, J. B. (2005). Social comparison in the classroom: Is there a tendency to compare upward in elementary school?. Current Research in Social Psychology, 10, 166-187.

Ebeling, H., Porkka, T., Penninkilampi-Kerola, V., Berg, E., Järvi, S., \& Moilanen, I. (2003). Inter-twin relationships and mental health. Twin Research, 6, 334-343.

Festinger, L. (1954). A theory of social comparison processes. Human Relations, 7, 117-140.

Fortuna, K., Goldner, I., \& Knafo, A. (2010). Twin relationships: A comparison across monozygotic twins, dizygotic twins, and non-twin siblings in early childhood. Family Science, 1, 205-211.

Fraley, R. C., \& Tancredy, C. M. (2012). Twin and sibling attachment in a nationally representative sample. Personality and Social Psychology Bulletin, 38, 308-316.
Gibbons, F. X., \& Buunk, B. P. (1999). Individual differences in social comparison: Development of a scale of social comparison orientation. Journal of Personality and Social Psychology, 76, 129-142.

Gilbert, P., Price, J., \& Allan, S. (1995). Social comparison, social attractiveness and evolution: How might they be related?. New Ideas in Psychology, 13, 149-165.

Huguet, P., Dumas, F., Marsh, H. W., Régner, I., Wheeler, L., Suls, J., ... Nezlek, J. (2009). Clarifying the role of social comparison in the big-fish-little-pond effect: An integrative study. Journal of Personality and Social Psychology, 97, 156170.

Huguet, P., Dumas, F., Monteil, J.-M., \& Genestoux, N. (2001). Social comparison choices in the classroom: Further evidence for students' upward comparison tendency and its beneficial impact on performance. European Journal of Social Psychology, 31, 557-578.

Huguet, P., Galvaing, M. P., Dumas, F., \& Monteil, J. M. (2000). The social influence of automatic responding: Controlling the uncontrollable. In J. P Forgas, K. D. Williams, \& L. Wheeler (Eds.) The social mind: Cognitive and motivational aspects of interpersonal behavior (vol. 2, pp. 371-388). Cambridge, UK: Cambridge University Press.

Huguet, P., Galvaing, M.-P., Monteil, J.-M., \& Dumas, F. (1999). Social presence effects in the Stroop task: Further evidence for an attentional view of social facilitation. Journal of Personality and Social Psychology, 77, 1011-1025.

Huguet, P., \& Monteil, J. M. (1995). The influence of social comparison with less fortunate others on task performance: The role of gender motivations or appropriate norms. Sex Roles, 33, 753-765.

Jonas, K. J., \& Huguet, P. (2008). What day is today? A socialpsychological investigation into the process of time orientation. Personality and Social Psychology Bulletin, 34, 353365.

Locke, K. D. (2003). Status and solidarity in social comparison: Agentic and communal values and vertical and horizontal directions. Journal of Personality and Social Psychology, 84, 619-631.

Locke, K. D. (2005). Connecting the horizontal dimension of social comparison with self-worth and self-confidence. Personality and Social Psychology Bulletin, 31, 795-803.

Locke, K. D. (2014). Agency and communion in social comparisons. In Z. Krizan \& F. X. Gibbons (Eds.) Communal functions of social comparison (pp. 11-38). Cambridge, UK: Cambridge University Press.

Lockwood, P., \& Kunda, Z. (1997). Superstars and me: Predicting the impact of role models on the self. Journal of Personality and Social Psychology, 73, 91-103.

Loehlin, J. C., \& Nichols, R. (1976). Heredity, environment, and personality: A study of 850 sets of twins. Austin, TX: University of Texas Press.

Luszczynska, A., Gibbons, F. X., Piko, B. F., \& Tekozel, M. (2004). Self-regulatory cognitions, social comparison, and perceived peers' behaviors as predictors of nutrition and physical activity: A comparison among adolescents in Hungary, Poland, Turkey, and USA. Psychology \& Health, 19, 577-593. 
Maccoby, E. E., \& Jacklin, C. N. (1974). The psychology of sex differences. Stanford, CA: Stanford University Press.

Major, B., Testa, M., \& Bylsma, H. (1991). Responses to upward and downward social comparison: The impact of esteemrelevance and perceived control. In J. Suls, \& T. A. Wills (Eds.) Social comparison: Contemporary theory and research (pp. 237-257). Hillsdale, NJ: Erlbaum.

Markus, H. R., \& Kitayama, S. (1991). Culture and the self: Implications for cognition, emotion, and motivation. Psychological Review, 98, 224-253.

Marsh, H. W., \& Hau, K. (2003). Big-fish-little-pond-effect on academic self-concept: A cross-cultural (26 country) test of the negative effects of academically selective schools. American Psychologist, 58, 364-376.

McGuire, S., \& Segal, N. L. (2013). Peer network overlap in twin, sibling, and friend dyads. Child Development, 84, 500511.

Mowrer, E. R. (1954). Some factors in the affectional adjustment of twins. American Sociological Review, 19, 468-471.

Multon, K. D., Brown, S. D., \& Lent, R. W. (1991). Relation of self-efficacy beliefs to academic outcomes: A meta-analytic investigation. Journal of Counseling Psychology, 38, 30-38.

Mussweiler, T. (2003). Comparison processes in social judgment: Mechanisms and consequences. Psychological Review, 110, 472-489.

Mussweiler, T., \& Bodenhausen, G. (2002). I know you are but what am I? Self-evaluative consequences of judging ingroup and out-group members. Journal of Personality and Social Psychology, 82, 19-32.

Mussweiler, T., \& Rüter, K. (2003). What friends are for! The use of routine standards in social comparison. Journal of Personality and Social Psychology, 85, 467-481.

Neale, M. C., Boker, S. M., Xie, G., \& Maes, H. H. (2006). $M x$ : Statistical modeling (7th ed.). Richmond, VA: Virginia Commonwealth University, Department of Psychiatry.

Neyer, F. J. (2002). Twin relationships in old age: A developmental perspective. Journal of Social and Personal Relationships, 19, 155-177.

Noller, P. (2005). Sibling relationships in adolescence: Learning and growing together. Personal Relationships, 12, 1-22.

Noller, P., \& Blakely-Smith, A. (2007). Competition and comparison in the relationships of adolescent siblings and twins. Family Relationships Quarterly, 5, 6-8.

Noller, P., Conway, S., \& Blakeley-Smith, A. (2008). Sibling relationships in adolescent and young adult twin and nontwin siblings: Managing competition and comparison. In J. P. Forgas, \& J. Fitness (Eds.), Social relationships: Cognitive, affective, and motivational processes. (pp. 235-252). New York, NY: Psychology Press.

Pelham, B. W., \& Wachsmuth, J. O. (1995). The waxing and waning of the social self: Assimilation and contrast in social comparison. Journal of Personality and Social Psychology, 69, 825-838.

Penninkilampi-Kerola, V. (2005). Co-twin dependence, social interactions, and academic achievement: A populationbased study. Journal of Social and Personal Relationships, 22, 519-541.
Schunk, D. H. (1989). Self-efficacy and achievement behaviors. Educational Psychology Review 1, 173-208.

Segal, N. L. (1984). Cooperation, competition, and altruism within twin sets: A reappraisal. Ethology \& Sociobiology, 5, 163-177.

Segal, N. L., Graham, J. L., \& Ettinger, U. (2013). Unrelated look-alikes: Replicated study of personality similarity and qualitative findings on social relatedness. Personality and Individual Differences, 55, 169-174.

Segal, N. L., Hershberger, S. L., \& Arad, S. (2003). Meeting one's twin: Perceived social closeness and familiarity. Evolutionary Psychology, 1, 70-95.

Segal, N. L., McGuire, S. A., Miller, S. A., \& Havlena, J. (2008). Tacit coordination in monozygotic twins, dizygotic twins and virtual twins: Effects and implications of genetic relatedness. Personality and Individual Differences, 45, 607612.

Segal, N. L., Munson, J. E., Marelich, W. D., Goetz, A. T., \& McGuire, S. A. (2014). Meeting of minds: Tacit coordination in adolescent and adult twins. Personality and Individual Differences, 58, 31-36.

Seta, J. J. (1982). The impact of comparison processes on coactors' task performance. Journal of Personality and Social Psychology, 42, 281-291.

Spielberger, C. D., Gorsuch, R. L., Lushene, R. E., Vagg, P. R., \& Jacobs, G. A. (1970). Manual for the State-Trait Inventory. Palo Alto, CA: Consulting Psychologists.

Stewart, E. A. (2000). Towards the social analysis of twinship. British Journal of Sociology, 51, 719-737.

Suls, J., Martin, R., \& Wheeler, L. (2002). Social comparison: Why, with whom, and with what effect? Current Directions in Psychological Sciences, 11, 159163.

Swap, W. C., \& Rubin, J. Z. (1983). Measurement of interpersonal orientation. Journal of Personality \& Social Psychology, 44, 208-219.

Tancredy, C. M., \& Fraley, R. C. (2006). The nature of adult twin relationships: An attachment-theoretical perspective. Journal of Personality and Social Psychology, 90, 7893.

Taylor, S. E., \& Lobel, M. L. (1989). Social comparison activity under threat: Downward evaluation and upward contacts. Psychological Review, 96, 569-575.

Tesser, A. (1988). Toward a self-evaluation maintenance model of social behavior. In L. Berkowitz (Ed.), Advances in experimental social psychology, Vol. 21: Social psychological studies of the self: Perspectives and programs (pp. 181-227). San Diego, CA: Academic Press.

Tesser, A., \& Schwarz, N. (Eds.). (2001). Intraindividual processes. In Blackwell handbook of social psychology (pp. 436457). Malden, MA: Blackwell.

Thorpe, K. (2003). Twins and friendships. Twin Research, 6, 532-535.

Veldkamp, S. A., van Bergen, E., de Zeeuw, E. L., Van Beijsterveldt, C. E., Boomsma, D. I., \& Bartels, M. (2017). Bullying and victimization: The effect of close 
companionship. Twin Research and Human Genetics, 20, 19-27.

Watzlawik, M. (2009). The perception of similarities and differences among adolescent siblings: Identification and deidentification of twins and non-twins. Journal of Adolescent Research, 24, 561-578.

Wheeler, L., \& Suls, J. (2007). Assimilation in social comparison: Can we agree on what it is?. International Review of Social Psychology/Revue Internationale de Psychologie Sociale, 20, 31-51.

Wills, T. A. (1981). Downward comparison principles in social psychology. Psychological Bulletin, 90, 245271.

Wood, J. V. (1989). Theory and research concerning social comparisons of personal attributes. Psychological Bulletin, 106, 231-248.

Wood, J. (1996). What is social comparison and how should we study it?. Personality and Social Psychology Bulletin, 22, 520-537.

Yoon, Y.-S., \& Hur, Y.-M. (2006). Twins have slightly higher self-concepts than singletons in the elementary school period: A study of South Korean twins and singletons. Twin Research and Human Genetics, 9, 233-239.

Zazzo, R. (1960). Les jumeaux le couple et la personne [Twins as a pair and as individuals] (2 vols.). Oxford, England: Presses Universitaires de France.

Zazzo, R. (1976). The twin condition and the couple effects on personality development. Acta Geneticae Medicae et Gemellologia, 25, 343-352.

\section{Appendix A}

\section{Anxiety Scale}

Each participant indicated to what extent he/she agreed or disagreed with each of the eight following items: «While taking the tests, you felt anxious», «comfortable», «jittery», «worried», «at ease», «nervous», «relaxed», and «calm». We used a 6-point scale that ranged from: (1) Strongly agree (2) Agree (3) Mostly agree (4) Mostly disagree (5) Disagree and (6) Strongly disagree. Items $2,5,7$, and 8 were reverse coded. A higher score indicated higher anxiety. Cronbach's alphas (taking the twin pair as unit of analysis) were high and identical inboth groups ( $\alpha \mathrm{MZ}$ and $\alpha \mathrm{DZ}=0.91)$.

\section{Appendix B}

Items and Factor Loadings for the Two Versions of the SCO Scale (General vs. Co-twin).

\begin{tabular}{|c|c|c|}
\hline \multicolumn{3}{|l|}{ A General Version } \\
\hline Items & $\mathrm{F} 1$ & $\mathrm{~F} 2$ \\
\hline $\begin{array}{l}\text { 1. I often compare how my loved ones } \\
\text { (boy or girlfriend, family members, } \\
\text { etc.) are doing with how others are } \\
\text { doing }\end{array}$ & 0.66 & 0.21 \\
\hline $\begin{array}{l}\text { 2. I always pay a lot of attention to } \\
\text { how I do things compared with } \\
\text { how others do thing }\end{array}$ & 0.78 & 0.14 \\
\hline $\begin{array}{l}\text { 3. If I want to find out how well I have } \\
\text { done something, I compare what I } \\
\text { have done with how others have } \\
\text { done }\end{array}$ & 0.75 & 0.11 \\
\hline
\end{tabular}

\section{Appendix B Continued}

\begin{tabular}{|c|c|c|}
\hline $\begin{array}{l}\text { 4. I often compare how I am doing } \\
\text { socially (e.g., social skills, } \\
\text { popularity) with other people }\end{array}$ & 0.76 & 0.24 \\
\hline $\begin{array}{l}\text { 5. I am not the type of person who } \\
\text { compares often with others } \\
\text { (reversed) }\end{array}$ & 0.72 & 0.07 \\
\hline $\begin{array}{l}\text { 6. I often compare myself with others } \\
\text { with respect to what I have } \\
\text { accomplished in life }\end{array}$ & 0.68 & 0.37 \\
\hline $\begin{array}{l}\text { 7. I often like to talk with others about } \\
\text { mutual opinions and experiences }\end{array}$ & 0.10 & 0.58 \\
\hline $\begin{array}{l}\text { 8. I often try to find out what others } \\
\text { think who face similar problems as I } \\
\text { face }\end{array}$ & 0.08 & 0.88 \\
\hline $\begin{array}{l}\text { 9. I always like to know what others in } \\
\text { a similar situation would do }\end{array}$ & 0.18 & 0.83 \\
\hline $\begin{array}{l}\text { 10. If I want to learn more about } \\
\text { something, I try to find out what } \\
\text { others think about it }\end{array}$ & 0.24 & 0.72 \\
\hline $\begin{array}{l}\text { 11. I never consider my situation in life } \\
\text { relative to that of other people } \\
\text { (reversed) }\end{array}$ & 0.68 & 0.05 \\
\hline $\begin{array}{l}\text { B. Co-twin version } \\
\text { Items }\end{array}$ & F1 & F2 \\
\hline $\begin{array}{l}\text { 1. I often compare how my co-twin is } \\
\text { doing with how others are doing }\end{array}$ & 0.70 & 0.39 \\
\hline $\begin{array}{l}\text { 2. I always pay a lot of attention to } \\
\text { how I do things compared with } \\
\text { how my co -twin do thing }\end{array}$ & 0.80 & 0.35 \\
\hline $\begin{array}{l}\text { 3. If I want to find out how well I have } \\
\text { done something, I compare what I } \\
\text { have done with how my co-twin has } \\
\text { done }\end{array}$ & 0.79 & 0.23 \\
\hline $\begin{array}{l}\text { 4. I often compare how I am doing } \\
\text { socially (e.g., social skills, } \\
\text { popularity) with co-twin }\end{array}$ & 0.83 & 0.07 \\
\hline $\begin{array}{l}\text { 5. I am not the type of person who } \\
\text { compares often with my co-twin } \\
\text { (reversed) }\end{array}$ & 0.85 & 0.23 \\
\hline $\begin{array}{l}\text { 6. I often compare myself with my } \\
\text { co-twin with respect to what I have } \\
\text { accomplished in life }\end{array}$ & 0.86 & 0.07 \\
\hline $\begin{array}{l}\text { 7. I often like to talk with my co-twin } \\
\text { about mutual opinions and } \\
\text { experiences }\end{array}$ & 0.07 & 0.89 \\
\hline $\begin{array}{l}\text { 8. I often try to find out what my } \\
\text { co-twin thinks when facing similar } \\
\text { problems as I face }\end{array}$ & 0.18 & 0.94 \\
\hline $\begin{array}{l}\text { 9. I always like to know what my } \\
\text { co-twin in a similar situation would } \\
\text { do }\end{array}$ & 0.30 & 0.87 \\
\hline $\begin{array}{l}\text { 10. If I want to learn more about } \\
\text { something, I try to find out what my } \\
\text { co-twin thinks about it }\end{array}$ & 0.39 & 0.81 \\
\hline $\begin{array}{l}\text { 11. I never consider my situation in life } \\
\text { relative to that of my co-twin } \\
\text { (reversed) }\end{array}$ & 0.54 & 0.41 \\
\hline
\end{tabular}

Note: A principal-component analysis (PCA) on the general SCO scale (11 items) was conducted on the whole sample of twins. The raw data was the mean score of the pair for each item. Although before rotations all items loaded on the first factor $(>0.40)$, two factors similar to those found by Gibbons and Buunk (1999) were extracted with eigenvalue $>1$. These factors explained $41.82 \%$ and $16 \%$ of the variance, respectively. After varimax (orthogonal) rotations, Factor 1, labeled 'Ability' by Gibbons and Buunk (1999), comprised items \#1 to \#6 (5 of which concerned performance); Factor 2, labeled 'Opinion', comprised items \#7 to \#10. The PCA conducted on the co-twin version of the $\mathrm{SCO}$ scale showed the same factor structure. Statistical analyses on the two sub-scales (Ability and Opinion) showed a higher SCO score on the Opinion sub-scale relative to the Ability sub-scale whatever the version of the SCO scale (General vs. Co-twin), and provided no additional information on the differences between $\mathrm{MZ}$ and $\mathrm{DZ}$, compared to those obtained on the full scales. 